\title{
Activating Knowledge \\ Through Electronic Collaboration: Vanquishing The Knowledge Paradox
}

\author{
S. Qureshi and P. Keen
}

\begin{tabular}{|l|l|}
\hline \multicolumn{2}{|l|}{ ERIM REPORT SERIES RESEARCH IN MANAGEMENT } \\
\hline ERIM Report Series reference number & ERS-2004-058-LIS \\
\hline Publication & July 2004 \\
\hline Number of pages & 21 \\
\hline Email address corresponding author & squreshi@mail.unomaha.edu \\
\hline Address & Erasmus Research Institute of Management (ERIM) \\
& Rotterdam School of Management / Rotterdam School of \\
& Economics \\
& Erasmus Universiteit Rotterdam \\
& P.O. Box 1738 \\
& 3000 DR Rotterdam, The Netherlands \\
& Phone: +31 10 408 1182 \\
& Fax: +31 10 408 9640 \\
& Email: info@erim.eur.nl \\
& Internet: www.erim.eur.nl \\
\hline
\end{tabular}

Bibliographic data and classifications of all the ERIM reports are also available on the ERIM website: www.erim.eur.nl 


\title{
ERASMUS RESEARCH INSTITUTE OF MANAGEMENT
}

\author{
REPORT SERIES \\ RESEARCH IN MANAGEMENT
}

\begin{tabular}{|c|c|c|}
\hline \multicolumn{3}{|c|}{ BIBLIOGRAPHIC DATA AND CLASSIFICATIONS } \\
\hline Abstract & \multicolumn{2}{|c|}{$\begin{array}{l}\text { Electronic collaboration has become a driver for productivity as organizations develop linkages } \\
\text { for the planning, sourcing and execution of goods and services. These organizations require } \\
\text { mechanisms to harness the diverse and personalized intellectual resources that are distributed } \\
\text { across the world. While electronic collaboration technologies have made it possible to harness } \\
\text { intellectual resources across space and time, knowledge management is locked in a } \\
\text { paradox of perception - the more valuable a knowledge resource is seen to be the less it is } \\
\text { shared. This paper develops framework for the activation of knowledge that relies on a view of } \\
\text { knowledge-as-identity. The analysis of a case study reveals "activation effects" that delineate } \\
\text { processes in which electronic collaboration technologies can be most effective. This has } \\
\text { implications for the creation of collaborative work environments that enhance activation in } \\
\text { organizations. }\end{array}$} \\
\hline \multirow{3}{*}{$\begin{array}{l}\text { Library of Congress } \\
\text { Classification } \\
(\mathrm{LCC})\end{array}$} & $5001-6182$ & Business \\
\hline & $5201-5982$ & Business Science \\
\hline & HD 30.3 & Communication of Information \\
\hline \multirow{4}{*}{$\begin{array}{l}\text { Journal of Economic } \\
\text { Literature } \\
\text { (JEL) }\end{array}$} & M & Business Administration and Business Economics \\
\hline & M 11 & Production Management \\
\hline & R 4 & Transportation Systems \\
\hline & L 15 & Information \\
\hline \multirow{4}{*}{$\begin{array}{l}\text { European Business Schools } \\
\text { Library Group } \\
\text { (EBSLG) }\end{array}$} & $85 \mathrm{~A}$ & Business General \\
\hline & $260 \mathrm{~K}$ & Logistics \\
\hline & $240 \mathrm{~B}$ & Information Systems Management \\
\hline & $240 \mathrm{~B}$ & Information Systems Management \\
\hline \multicolumn{3}{|c|}{ Gemeenschappelijke Onderwerpsontsluiting (GOO) } \\
\hline \multirow[t]{4}{*}{ Classification GOO } & 85.00 & Bedriffskunde, Organisatiekunde: algemeen \\
\hline & 85.34 & Logistiek management \\
\hline & 85.20 & Bestuurlijke informatie, informatieverzorging \\
\hline & 85.20 & Bestuurlijke informatie, informatieverzorging \\
\hline \multirow[t]{3}{*}{ Keywords GOO } & \multicolumn{2}{|c|}{ Bedrijfskunde / Bedrijfseconomie } \\
\hline & \multicolumn{2}{|c|}{ Bedrijfsprocessen, logistiek, management informatiesystemen } \\
\hline & \multicolumn{2}{|c|}{ Kennisoverdracht, samenwerking, kennismanagement } \\
\hline Free keywords & \multicolumn{2}{|c|}{$\begin{array}{l}\text { activation, knowledge-as-identity, knowledge paradox, accountable knowledge, discretionary } \\
\text { knowledge, autonomous knowledge }\end{array}$} \\
\hline
\end{tabular}




\title{
Activating Knowledge through Electronic Collaboration: Vanquishing the Knowledge Paradox
}

\author{
Sajda Qureshi \\ Department of Information Systems and Quantitative Analysis \\ College of Information Systems \&Technology \\ University of Nebraska Omaha \\ and \\ Rotterdam School of Management \\ Erasmus University Rotterdam \\ Email: squreshi@mail.unomaha.edu \\ Peter Keen \\ Department of Information and Communication Technology \\ Faculty of Technology, Policy, and Management \\ Delft University of Technology \\ The Netherlands \\ Email: peter@peterkeen.com
}

\begin{abstract}
Electronic collaboration has become a driver for productivity as organizations develop linkages for the planning, sourcing and execution of goods and services. These organizations require mechanisms to harness the diverse and personalized intellectual resources that are distributed across the world. While electronic collaboration technologies have made it possible to harness intellectual resources across space and time, knowledge management is locked in a paradox of perception - the more valuable a knowledge resource is seen to be the less it is shared. This paper develops framework for the activation of knowledge that relies on a view of knowledge-asidentity. The analysis of a case study reveals "activation effects" that delineate processes in which electronic collaboration technologies can be most effective. This has implications for the creation of collaborative work environments that enhance activation in organizations.
\end{abstract}

\section{Introduction}

Electronic collaboration is the purposeful use of networking and collaborative technologies to support groups in the creation of shared understanding. This concept has been developed through many years of research in how people use various collaborative technologies to achieve their tasks and objectives (refer to Qureshi and Vogel (2000) and Powell et al (2004) for a review of this literature). It appears that the use of collaborative technologies to support organizational processes has the potential to increase productivity in organizations (Lipnack and Stamps 1997, Robey et al 2000, Nunamaker et al 1989). Research carried out by Koch (2001) suggests that processes such as the compensatory adaptation to lean media brings about a "positive" effect on the quality of outcomes. In their study of multiple geographically and temporally dispersed teams, Rutkowski et al (2002) draw special attention to the structure of electronic communication required to support efficient virtual teaming. It appears that a complex set of social factors govern collaborative 
technology use in organizations. Some even suggest that collaborative technologies such as email actually increase hierarchy in organizations (Perin 1991, Qureshi 1996).

Collaborative commerce has been associated with the need for organizations to work together in planning, sourcing and the execution of goods and services. Scott Kownlar (2004) suggests that "E-business as a concept is being redefined to include not just transaction making, but other collaborative activities that leverage the Web as well". There is a sense that as people and organizations do business with each other over the web, the need for collaborative technologies, processes and structures will be come necessary (Kownlar 2004, Alexander 2000). Electronic collaboration in collaborative commerce settings is governed by the use of knowledge and expertise to provide customized goods and services. There is agreement that in order to be able to provide customized goods and services, the effective performance and growth of organizations requires integrating and sharing highly distributed knowledge (Zack 1999, Quinn 1992, Nonaka and Takeuchi 1995). Distributed knowledge is often personalized and resides in the pockets and communities within the organization. This knowledge is also seen to form the core competence of the intelligent enterprise and has to be supported if the organization is to remain competitive Quinn (1992).

Efforts to date in knowledge management have largely concentrated on codifying or explicating knowledge. Infrastructures are proposed for storing explicit knowledge as well as refining, managing and distributing it (such as Zack 1999, Hansen et al 1999). While these efforts are valuable in themselves, practical considerations such as motivating employees to add to such databases and use them in their "knowledge work" have thwarted the success of such codification strategies. Ruppel and Harrington (2001) suggest that resistance to intranets as a knowledge sharing environment is a management and corporate issue rather than a technology issue. This paper suggests that a paradox exists in that the building and sharing of knowledge is one of the highest sources of advantage for an organization, but also the most guarded resource. Two of the most frequent explanations of these barriers are (1) the lack of incentives to share knowledge and often strong reasons to protect and hoard it (Hibbard, and Carillo 1998) (2) the lack of mechanisms to make it easy to organize and access knowledge resources (Bechky 2003, Ruppel and Harrington 2001). In addition, Bechky (2003) suggests that as certain expressions could potentially signify multiple contents, an expression could mean something different to the receiver than it does to the communicator. Furthermore, the occupational communities within organizations 
can be expected to have different domains of knowledge that are dispersed across different individuals.

A major challenge remains one of harnessing the power of these "knowledge" networks of distributed knowledge (Davenport et al 1996, Powell 1991, Sowell 1996). The challenge is deeprooted, dating back to Barnard's conception of the organization as driven by the need to build and share intelligence (Barnard 1938, Williamson et al, 1995), with a long tradition of research on organizational learning (Argyris and Schoen, 1978), Senge (1990), and intellectual capital (Stewart, 1997). By leveraging the creation and use of this key resource, new levels of organizational effectiveness can be attained (Nonaka and Takeuchi (1995), Drucker (1993), Quinn (1992). The challenge is to mobilize this hidden manpower (Eon and Lee 1999). There is a recognition that electronic collaboration has the potential to leverage this key resource (Schrage 1990, Lea et al 1995). However, it is as yet unclear as to how electronic collaboration can leverage knowledge resources.

This paper investigates how electronic collaboration can be used to harness an organization's knowledge resource and activate it towards joint effect. It develops a theoretical framework for the activation of knowledge. This framework suggests that activating personalized knowledge is firstly about identifying knowledge as part of the person, secondly it requires the existence of multiple activation networks and thirdly spaces through which knowledge can be activated. Such activation networks emerge through communities of practice (Wenger 1998, Lave and Wenger 1991), industrial networks (Galaskeiwicz 1979) and social relationships (Weick 1989) where knowledge, expertise and experiences are activated as and when needed. A case study of a multinational organization is conducted that reveals certain "activation effects" that are needed to activate knowledge. The results and analysis suggest a noteworthy role for electronic collaboration in overcoming the knowledge paradox.

\section{A Framework for Knowledge Activation: Knowledge-as-Identity}

Knowledge activation is the conversion of knowledge into action. Activating knowledge is about finding people with relevant knowledge and using it effectively through their willingness to provide, access and share it as and when needed. Activation, explains Galaskeiwicz (1979), is being at the centre of resource networks. This gave people in the organisations that he studied, access to a greater number of other organisations that could provide them with the necessary resources. Because the likelihood of mobilizing resources is much greater for actors in the centre of social networks, they 
could more confidently engage the political process - the process of influencing other actors and mobilizing resources for collaborative initiatives. In addition, Knoke and Kulksinki (1991) found that by cultivating diversified ties to large numbers of community organisations capable of supplying resources, a group's dependence on a single source can be significantly reduced. This suggests that activating knowledge can reduce an organization's dependence on a single set of experts or extend the organization's access to expertise from other organizations or communities.

The role of meaning, particularly the creation of shared meaning in organizations, takes us a long way towards understanding the translation of knowledge to purposeful action - hence activation. Theories of changing perceptions of stimuli (Daft \& Weick, 1984), theories of personal knowledge creation (Nonaka and Takeuchi 1995) based upon tacit and explicit knowledge (Polyani 1966), and the processes of how to deal with these types of knowledge (Boisot,1998) suggest that there are multiple dimensions of knowledge. According to Duncan and Weiss (1979) organizational learning consists of producing communicable, consensual and integrated knowledge. Organizational learning is often seen as an emergent, holistic process of sensemaking through the creation of mental models (Senge 1990, Weick, 1989) or a distinct dynamic spiral (Argyris and Schoen, 1978). This builds upon Daft and Weick's (1984) model of organizations as interpretation systems. Duncan and Weiss (1979) suggest that although the individual is the only entity in the organization that can learn, this must be viewed as part of a system of learning with exchanges of what is learned among individuals. While these views do not make the identity of the individual explicit, they suggest that knowledge is perceptual and is created through the individual. This paper takes this notion a step further and suggests that learning is shaped by individual knowledge identities: this can be accountable and part of an individual's professionals life, or discretionary that is theirs to share voluntarily, or autonomous knowledge that forms their private experience. The following Figure 1, illustrates the theoretical framework of Knowledge Activation that we investigate in this paper. 


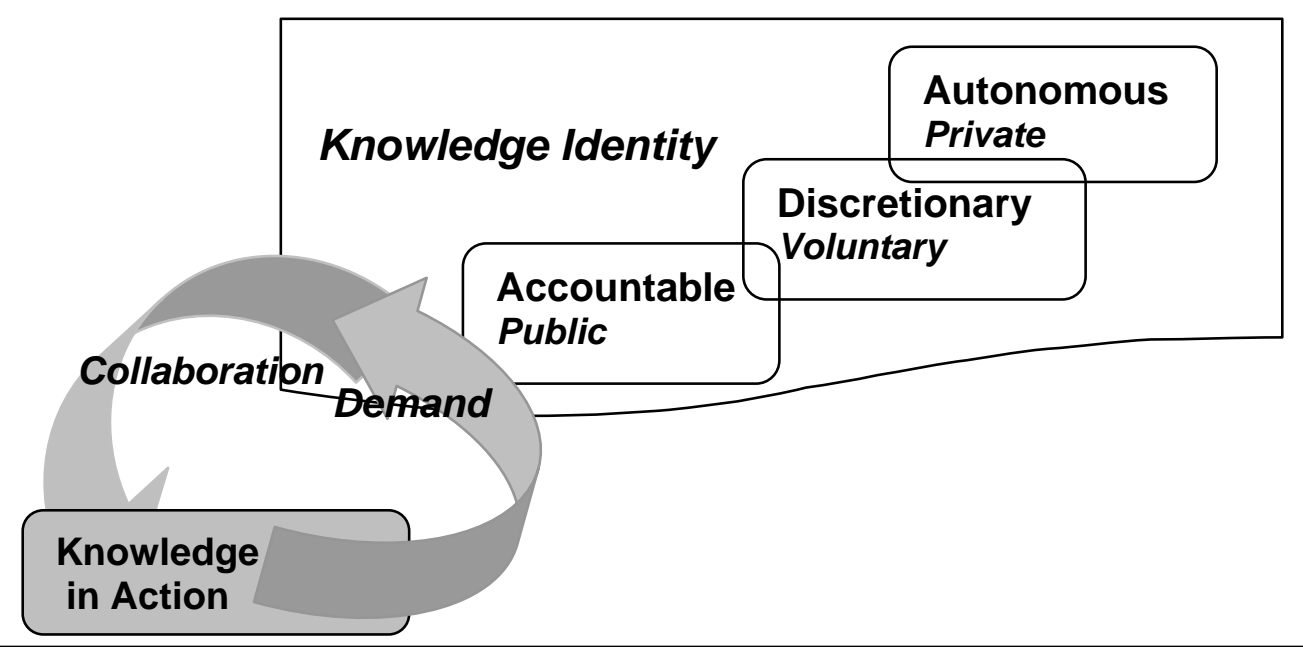

Figure 1: Theoretical Framework of Knowledge Activation

Accountable Knowledge is the knowledge that is part of the public identity and responsibility of an individual, group or profession. Professionals are accountable for the building, use and sharing of knowledge, either as part of their professional identity or their formal position and role in the organization. Accountable knowledge is both role and domain-specific: A CPA, professor or sales manager is accountable to the communities who recognize and draw on their public identity.

Discretionary Knowledge is considered a gift to be presented voluntarily as there is no accountable responsibility to share it. The individual announces a willingness to do so and thus opens up his or her private identity and makes the knowledge part of public identity. The decision to contribute to a virtual community requiring discretionary knowledge is voluntary.

Autonomous Knowledge is part of an individual's private identity and is not easily shared. This knowledge is both tacit and experiential and a decision to share it is highly personal. It is core to one's sense of self. It is mobilized - made active - in personal relationships, including friendships and mentoring, and in particular types of communities.

Knowledge produced by individuals is used when it becomes exchanged and accepted by others. This is knowledge in action. Knowledge in action is determined by the knowledge identities of individuals and the network in which their knowledge - tacit or explicit is activated. In order to activate knowledge, there has to be a demand for it in the form of a request placed within an 
activation network. Once demand for action has been communicated, collaboration activates the knowledge identities needed for knowledge to be used in action.

Collaboration is the commitment to the act of constructing relevant meanings that are shared by all parties involved in the achievement of congruent goals. Collaboration is needed to 1) determine what action is required and is relevant, 2) determine what knowledge is required to carry out the required action and 3 ) initiate demand for action. Together, these three aspects enable activation or the use of knowledge to create a joint product or service. In order for collaboration to take place, relevant knowledge must be communicated by members who take part in the networks.

Demand for action is the trigger that brings about the activation of knowledge. Activation of knowledge on demand depends upon the power of a particular request. Acquiring power through corporate networks is very much akin to Rosabeth Moss Kanter's (1988) studies that illustrate how mobility of certain individuals between parts of organisations and to other organisations serves as a mechanism for building up the power of certain groups and individuals. Elements of cohesion within a network relative to that of another may provide an indication of the extent to which power and control is potentially exercised over the collective resources of a particular network. Sometimes, looking at the positions on the network may provide an indication of the type and level of authority that actors occupying certain positions possess. This suggests that demand for action has to be coupled with the authority to initiate activation or a legitimacy recognized by other members in the network.

\section{Research Approach}

Case study research was carried out to enable theory to be further developed through a process of disciplined imagination or sensemaking (Weick 1989). A grounded theory approach was used for the discovery of theory from data systematically gathered and analyzed from the research process (Glaser and Straus 1967, Straus and Corbin 1998). The data collected in this case study was analyzed using the concepts of knowledge activation to categorize the data. Theory generated from data can usually not be completely refuted by more data or replaced by an alternate theory. Within this approach, theory is discovered first, through conceptual categories and their conceptual properties; and second, through hypotheses or generalized relations among the categories and their properties (Glaser and Strauss 1967). This paper concentrates on the former for the discovery of theoretical concepts and relationships. 
Theoretical sampling is used to collect, code and analyze the data. On this basis, the researcher decided what data to collect next and where to find it in order to develop the theory further (Glaser and Straus 1967). Data was gathered through interviews, observations and electronic transcripts of newsgroup and community interaction. This data was analyzed using a grounded theory approach. Conceptual categories and their properties were identified in the interviews and transcripts of electronic collaboration using Straus and Corbin's (1998) open coding method. During open coding, data are broken down into discrete parts, closely examined and compared for similarities and differences. Events, happenings, actions and interactions that are found to be conceptually similar in nature or related in meaning are grouped under more abstract concepts. In the following case study, the conceptual properties of activation are discovered and then relations between these concepts sought.

\section{Case Study: Knowledge Activation at Galaxy Corporation}

The case chosen to investigate Knowledge Activation is a multi-national information technology and business services organization that is the result of a merger. In order to protect its privacy, we call this merged company, Galaxy Corporation and its two separate merged entities Starnet and Global Consultancy. The concept of an intelligent enterprise rings true to Galaxy Corporation as it provides customized services by selling the skills and intellects of its key professionals. The merged organization, Galaxy Corporation, has a significant presence in 20 countries in Europe, the USA and in Asia. The Galaxy Corporation Group businesses are diverse and include management consulting, information technology consulting, systems integration, to software development, outsourcing and training. By June of 2001 the Group had close to 60,000 employees across the world.

\section{Collaborative Technology Infrastructure}

This case is particularly appropriate for a study of knowledge activation through the use of electronic collaboration because a elaborate suite of collaborative technologies have been made available on the company's intranet for the purpose of sharing knowledge. The information and communication facilities available on Starnet's CapCom intranet are the Knowledgebank, which is a database of documents and other information, email, newsgroups and homepages relating to various functions, units and training programs. This is not a standard intranet application as more sophisticated tools are available, such as the Knowledge Marketplace, Virtual Rooms, and My Galaxy. In addition, Sibylle is a sophisticated natural language query tool available to all the Galaxy Corporation consultants. Consultants can make My Galaxy fit their personal information and 
communication needs by customizing every function that is available on My Galaxy. The appropriation of this technology leads to the emergence of very personalized workspaces. Consultants make their own selection of on line newspapers (a few are standard), own newsgroups, Internet and Intranet sites and choice of communication and collaboration tools. Once consultants have configured My Galaxy, they can work at any place, at any time, on any computer in the world (an Internet connection is all that is needed to find their galaxy). The configuration of each personalized workspace is stored on the My Galaxy central server.

\section{Results and Analysis}

The results are derived from data collected just prior to and after the merger of Starnet and Global Consultancy into Galaxy Corporation; the data was collected from May 2000 until December 2000. The data comprise open interviews and transcripts of electronic collaboration using Starnet's intranet based knowledge management system. This data are analyzed using the theoretical framework of knowledge activation developed above. In addition to our data, this analysis also draws upon the results of a usability survey conducted in 1999 by Starnet, prior to the merger with Global Consultancy. This survey evaluates employee satisfaction with respect to information provision, the communication and collaboration facilities available through the company's intranet.

The data was organized into conceptual categories and further refined using open coding. The main types of collaborative effort that emerged from coding the transcripts are illustrated in the following labels: sharing of advice, requesting clarification, sharing ideas/thoughts, references to sources and training programs. In some interactions, people meet electronically and then continue interactions through a face to face or telephone communication. The following sections distil these results from our analysis and ascertain the knowledge activation concepts.

\section{Activation of Accountable Knowledge}

Accountable knowledge is activated because there is demand for action. Consultants within Galaxy Corporation have to develop and deliver customized solutions for clients problems. The development of such products or solutions takes place in teams with members from different disciplines that bring to bear their experiential and explicit knowledge for which they are accountable. Such teams may often include people from the client organization. In order to deliver customized products and solutions, the consultants of Galaxy Corporation must be able to work with each other as well as with the employees of their clients. This is consistent with Ruppel and Harrington's (2001) findings that suggest that organizational culture and work practices are a factor 
in the adoption and implementation of intranets. The advantage of using such network technologies is that they allow new knowledge to be combined with existing information to generate and systematize knowledge throughout the organization (Nonaka and Takeuchi 1995).

Within My Galaxy is the Virtual Project Room. This is a tool for electronic collaboration which enables accountable knowledge to be activated every time there is demand for action. The following example illustrates this: Alan is working in a project for a client organization. There is demand for his action as software developed within this project will be used in five other organizations also involved in this project. The project members from Galaxy Corporation are working from several different places and hold information and knowledge relevant and critical to the success of this project. Their knowledge needs to be activated through communication and collaboration. The Virtual Project Room is used to activate, share and develop knowledge on this project. Figure 2 illustrates how accountable knowledge is activated by Alan who is working at home using the Virtual Project Room.

Alan is working at home today because he has to write a final report. When he starts in the morning he logs in at his Virtual Project Room to check the latest news and download a draft of the final report he started on yesterday. He finds the latest news on the program dashboard and finds his document in the developing work stream. He downloads the document on which his colleagues have been working and begins finalizing it. At the beginning of the afternoon he has some queries about the data in the report and he posts these in a note on his work stream. Within half an hour one of his colleagues responds with a review of the data in a new note. Alan does not understand the review and starts a NetMeeting session with this colleague. On-line the consultants discuss the data, the review and come to a solution. At the end of the afternoon Alan puts the finalized document back in the virtual office so that the other members of the project can read and review the document. It is especially important that the project members who are part of the client organization read it. In this way, Alan feels that he has been able to work more effectively at a distance.

\section{Figure 2: Activation of Accountable Knowledge}

In the space provided by the Virtual Project Room information on projects and status is shared. Consultants and the members of Galaxy Corporation's client organization can use different levels of functionality within the Virtual Project site. The project manager or consultant responsible for the project ensures that all the necessary information is visible at the top project level. In order to activate accountable knowledge so that it may be used in action, certain "activation effects" need to be in place. These are the existence of shared spaces and support as described in the following sections. 


\section{Shared Spaces}

In order to activate accountable knowledge, shared spaces are needed through which different project members can communicate and create shared understanding. Virtual Office (VO) is an electronic shared space used by Galaxy Corporation professionals who work on large projects that span a number of different sites. VO is a web-enabled communication tool accessible at the project level and is combined with My Galaxy. The VO contains several levels of information relating to the project(s) being undertaken, work-packages or work-streams, and personal information relating to participants within projects. A special project administrator compiles a list of members on the project. These may be Galaxy Corporation professionals and also members of the Galaxy Corporation's client organizations. They all receive an identification and a password in order to access this facility through the intranet and post information. Such shared spaces form the boundary objects that mediate cultural differences between the consultants: the English consultants work very differently than the Dutch and the French consultants have certain characteristics to be taken into account. Qureshi et al (2000) found that such electronic spaces enable the accommodation of different perspectives to take place. This is consistent with Inkpen and Dinur's (1998) findings in that intranets facilitate communication and interaction and create a knowledge connection.

\section{Support}

A person's accountable knowledge can be activated by a number of different people, or organizations demanding action. The exchange of information and social support took place through the newsgroups, among other face to face and phone interactions. However, the newsgroups were used by $44.6 \%$ of the respondents to communicate needs and share information. According to the usability survey, $78 \%$ of the respondents said they preferred to search for the information that they need (using Sibylle) and read the newspages/newsfeeds. This suggests that updating accountable knowledge had high priority. The electronic news desk, the FTP site and the division and unit pages rate higher (average 6,8 out of 10) than the other information and communication tools. Accountable knowledge is updated through several information ordering tools known as news, notes, files/documents, events, activity/to do list and forums. These findings are consistent with El-Shinnawy and Markus (1998) in that media features of functionality, usability and ease of use were found to have a major influence on media choice. Blanchard and Markus (2004) suggest a feeling of belonging is important in a virtual community. They found that while support was an important part of the community, it was informational and not 
social (and emotional) support that was considered most important. It appears that it is informational support that enables accountable knowledge to remain updated.

\section{Activation of Discretionary Knowledge}

When accountable knowledge is not sufficient to satisfy a demand for action, discretionary knowledge is activated. This is why the division and unit homepages are more often accessed in comparison to the other facilities. According to a survey carried out of Starnet's employees, $70 \%$ of the respondents use the homepages frequently compared to $61.5 \%$ use email frequently, $44.6 \%$ use the newsgroups frequently and only $19.8 \%$ used the Knowledgebank frequently. Only $10 \%$ of the employees stated that they had trouble sharing knowledge. The rest did so regularly in various ways. One popular site for sharing knowledge (not available at the time of Starnet's survey) was the Knowledge Marketplace where consultants would put up a question relating to a specific problem they experienced in the project that they were working on. Often the answer to such problems lie in experiential, and personalized knowledge held by various members of the organization but not necessarily related to their job description. The Knowledge Marketplace was a site on Galaxy corporation's intranet that contained spaces marked by icons that looked like stalls. Each stall was facilitated by one or two consultants in their area on interest but not necessarily expertise. An example of such a stall was "data dictionaries". As expertise was not evenly distributed in the organization, people needed to tap into each other's expertise that was distributed across the organization. While the existence of this social network was known, it was not clear who should be contacted for particular questions not answered through known experts. The Knowledge Marketplace harnessed this social network and enabled it to be activated. This tool mediated the knowledge sharing activities by connecting people with their world of objects/expertise and also with other people (Sherry and Meyers 1998, Engeström et al. 1995). A shared vocabulary emerged on this tool and interaction was mediated through a set of norms and rules.

Activation of discretionary knowledge through the Knowledge Marketplace took place as consultants would post questions specific to the topic of the stall. The answer would be given by any consultant, at their own discretion, who was able to provide an answer to the question. When someone posted a question or an answer was put on the market spot, the consultant whose market spot had been queried then received an email notification. An example is Martin, a Galaxy consultant, who working at a client site, is looking for a search engine for searching in directories and CD Roms for special documents. To find an answer he logs in through the Internet to the 
Galaxy Corporation's Knowledge Marketplace and asks his question. Figure 2 illustrates how the Knowledge Marketplace is used to activate discretionary knowledge.

Martin: "I am looking for a standard software component with which you can search through documents with several formats (Word, Powerpoint, etc.). The documents are on a CD Rom so the search engine must be server independent. It must be simple and straightforward."

Alan: "You can use Alta Vista, freeware for searching and indexing documents. Works specially for Word and Powerpoint. Within our group we have very good experience with the tool."

Peter: "You can use MS Index Server for building an automatic index"

Janis: "MS Index Server does not work with cd-rom. You have to think about ActiveX control as a plug in , in your browser for making an index. That is a lot of work. Other possibilities you find on www.progressivelogic.se, www.netresults-search.com or www.astaware.com."

Sandra: "MS Index server can not be used with cd-rom. Another solution is verity, but that is very expensive. "

\section{Figure 3: Activation of Discretionary Knowledge in the Knowledge Marketplace}

As a result of the above interaction on the Knowledge Marketplace, Martin decides to contact Janis by telephone. They discuss the matter, the options available to him and possible courses of action he can take. In the end Martin is able to follow an informed course of action based on his assessment of the information exchange that has taken place. The activation effects that were identified from such interactions on the Knowledge Marketplace are discussed in the following sections.

\section{Reciprocity}

Participants who had received answers to their queries through the knowledge marketplace were required to reciprocate when they had answers to or knew how to arrive at answers to questions posted on the market spot from which they had received assistance. The knowledge market place was seen to be a serious space on which no idle chats were allowed. The shared spaces on the knowledge market place were divided into consultant-defined subjects known as "market spots." A consultant known as the "midwife" was the facilitator responsible for managing their assigned market spot or "the maternity ward." This facilitator is responsible for ensuring that the facility is used to share relevant information. In addition, expectations of almost immediate response have also become a reality. This is illustrated in the following quotes:

"It [the Knowledge Marketplace] works. Five different people reacted to my one question!" 
Another consultant remarked: "Suppose the same question was put on the newsgroups and the knowledge marketplace. In my experience my question on the marketplace would be answered faster even though the number of potential respondents is ten times higher in the newsgroups."

This pattern of interaction is consistent with Burgoon et al. (2000) who found that successful outcomes in computer mediated group communication were related to higher levels of interactivity. They found processes of mutuality and involvement to be significant in effecting task outcomes. Partners perceived as more involved were judged as more credible and attractive to work with. Mutuality was also positively associated with credibility and attraction. The more participants felt that their partners were similar to them, the more they rated the partner as reliable, useful, friendly, dominant, trustworthy and attractive to work with (Burgoon et al. 2000). This suggests that in order to activate discretionary knowledge, reciprocal collaborative relationships need to be facilitated by fostering involvement and mutuality. In addition, virtual teams benefit from the presence of caretakers whose sole contribution is to support regular, detailed and prompt communication, as well as identifying individual role relationship and responsibilities (Powell et al. 2004).

\section{Relationship}

There was an extent to which the creation of relationships among participants had become an integral part of the practice. The activation network was particularly powerful: consultants from very different parts of Galaxy corporation found out about each other through interacting on the Knowledge Marketplace. As a result, they were able to work together on projects that they would otherwise have not been able to. The activation network developed as a result of interactions using the collaborative technologies has meant that consultants had free access to each others' expertise. They were no longer bound by organizational walls (departments, divisions) and or restricted to working on projects that fell within their own departments. As the identities of the participants in the Knowledge Marketplace was defined by their action, short biodatas of the facilitators of each stall were described in each market spot. In the case of an intranet site on which very diverse members of an organization interact on specific issues, it appears that relationships are built upon the activation of discretionary knowledge. The consultants who shared their experiential and often tacit knowledge at their discretion with strangers within their organization, tended to meet up with each other in a café or over the phone hence developing relationships with each other. Powell et al. (2004) suggest that if it is feasible for members to meet physically meet, these should focus on relationship building. Otherwise facilitating socialization through chat 
sessions or increased social communication can stimulate relationship building (Powell et al. 2004). Robey et al (2000) found that electronic communication improved social and emotional relations among workers in remote locations. They even found that a degree of intimacy was achieved with remote communication that spanned functional, geographic and cultural divides. It appears that even though relationships tend to develop through the initial activation of discretionary during electronic collaboration, activation of discretionary also knowledge requires the existence of more ongoing relationships.

\section{Activation of Autonomous Knowledge}

Working with clients requires a great deal of personal input. In order to work well with their clients consultants need to draw upon their personal experiences often delving into their private identities. The key mediating tools for activating autonomous knowledge were email, mobile phone and the newsgroups on the intranet. Collaboration with clients was seen to be a legitimate way of working while the extent to which there was collaboration among employees varied between units. From the transcripts of interactions in the Newsgroups, it is clear that a repertoire of technical jargon used in the consultants' work environments was also being used in the electronic spaces. Shared communication was mostly related to software and technical system development issues. In this process, private autonomous knowledge was brought into the collaborative arena. The use of collaborative technologies did enable conversations with new kinds of properties to emerge (Schrage 1990). Ideas that would have remained part of an individual's personal repertoire of knowledge, became both external and manipulatable. People were able create icons and textual imagery to represent ideas and concepts which others could modify or manipulate until they become both community property and a visual part of the conversation. According to Blanchard and Markus (2004), the affective bonds that differentiate between neighborhoods and true communities is "sense of community". In their study of a virtual community, Blanchard and Markus (2004) found three processes by which sense of community was reinforced: 1) exchange of information and socio-emotional support, 2) creating identities for themselves and creating identifications of others and 3 ) the production of trust. This suggests that activating autonomous knowledge implies a sense of community. This creation of sense of community is illustrated in the following Figure 4: 
JM: Who can help me find a product comparison of UML Modeling tools?

WL: Have you looked on the Gartner Group (www.gartner.com ?) site and searched Sibylle?

$\mathrm{PH}$ : Some good alternatives are GDPro reviewed by SD Magazine.

http://www.sdmagazine.com/articles/2000/0002/0002j/0002j.htm Or TogetherJ, which you can try at: http://www.togethersoft.com/together/togetherJ.html

$D S:$ Has anyone got templates of procedure handbooks for the management of Intranet content $(B B C M)$ ? Any information on the set up and management of content?

EL: At Warp11 we are busy putting together a handbook. Come and see us at our office and you can browse through a draft version.

\section{Figure 4 Activating Autonomous Knowledge in the Newsgroups}

Activating autonomous knowledge in the newsgroups was done by posting questions in exchange for information or support. Identities emerged through interactions on the newsgroups. Given the amount of personal knowledge that was being exchanged, it appears that trust was in the making. Such virtual interactions have expanded to off-line interactions and have become part of the life of the community. The activation effects identified for activating autonomous knowledge are discussed in the following sections.

\section{Trust}

Community members expose their personal feelings and share private knowledge if they trust other members of their community. The collaborative technologies were is set up to support that principle by stimulating two way communication rather than top-down communication. However, according to the survey results, only $25 \%$ of the employees felt that through My Galaxy they are "masters of their own destiny". Although the organizational culture at Galaxy Corporation is open, consultants do like to keep important knowledge and information to themselves. The reason for this is if particular business development or information system development techniques are made available electronically, the main concern is, how will they be used? The integrity of information and appropriate use by other consultants are seen to be very important. It has been suggested that high levels of trust and cohesiveness reduce barriers to communication in virtual teams and are instrumental in promoting cooperation (Powell et al. 2004, Jarvenpaa et al. 1998). Perceptions of members' benevolence and integrity are important in the development and maintenance of trust (Jaarvenpaa et al. 1998). It follows that the perception of trust has an important effect in activating autonomous knowledge. 


\section{Personalization}

Flexibility in the use of collaborative and information technologies to personalize individual work environments is important not only for activating autonomous knowledge but also for bringing it into the collaborative arena. Because of the merger, Galaxy Corporation's accepted work practices were in a state of dynamic redefinition. Collaboration through discussion groups, face to face team working and even simple telephone conversations are seen to be paramount. Individual consultants would personalize a project site for themselves where they would put personal activities, files, their personal address book and links to sites and newsgroups they used. In this way all project members were able to manage their own projects and could still be part of several projects. Different consultants worked in one or several work streams at the same time, and had access to the work streams in which they participated and to all the related information modules, contained in files, notes, news for their own stream. They would activate each others' knowledge and develop it using various discussion tools and email. In developing upon each other's ideas, consultants were able to be more creative and apply themselves to more innovative types of projects. Situated learning or learning by doing takes place in communities of practice where a sense of belonging and common interests have developed over time (Lave and Wenger, 1991). A community that develops is own organizational memory, serves the organization by encouraging learning and creativity without stifling emergent ideas (Morrison, Morrison and Vogel 1992). This suggests that personalized work environments are conducive to the activation of autonomous knowledge as they enable knowledge to be channeled towards more creative and innovative projects.

\section{Implications for Practice: Overcoming the Knowledge Paradox}

From the above analysis it appears that electronic collaboration has a mediating effect in the activation of knowledge. Collaborative technologies mediate activities carried out by different people with different levels of expertise and understanding who work in very different contexts. The process of collaborating electronically spans multiple boundaries (Engeström et al. 1995) and activities (Sherry and Myers 1998). The use of electronic collaboration technologies has made it possible in this study to harness intellectual resources across space and time. Yet the technology is only a part of the development and maintenance of the activation networks. These powerful networks are social and community based. As stated by one consultant "You cannot do everything through this contraption [My Galaxy and the Virtual Project Room] !!". Consultants feel that even though they may not relay on the collaborative technologies, electronic collaboration has meant 
that they can move through the organization more freely and innovative hybrid projects have become more commonplace. We know that the role of electronic communications to leverage networks of people in decision-making and innovation is a growing theme in research (Fulk and DeSanctis 1995, Desanctis and Monge 1988, Powell 1991) and practice (Lea et al. 1995, Drucker 1988, Charan 1991). We have found as a result of this research that electronic collaboration mediates the activation of knowledge identities. This is illustrated in the following Figure 5:

\begin{tabular}{|c|c|c|c|}
\hline $\begin{array}{l}\text { Knowledge } \longrightarrow \\
\text { Identities }\end{array}$ & $\begin{array}{l}\text { Activation } \longrightarrow \\
\text { Effects }\end{array}$ & $\begin{array}{l}\text { eCollaboration - } \\
\text { Mediators }\end{array}$ & $\begin{array}{l}\text { Knowledge } \\
\text { In Action }\end{array}$ \\
\hline $\begin{array}{l}\text { Accountable } \\
\text { Public }\end{array}$ & $\begin{array}{l}\text { Shared Spaces } \\
\text { Support }\end{array}$ & $\begin{array}{l}\text { Virtual Office } \\
\text { Newsfeeds/Svbill }\end{array}$ & $\begin{array}{l}\text { Product } \\
\text { Development }\end{array}$ \\
\hline $\begin{array}{l}\text { Discretionary } \\
\text { Voluntarv }\end{array}$ & $\begin{array}{l}\text { Reciprocity } \\
\text { Relationship }\end{array}$ & $\begin{array}{l}\text { Marketplace } \\
\text { Email/Homepaces }\end{array}$ & $\begin{array}{l}\text { Problem } \\
\text { Solvina }\end{array}$ \\
\hline $\begin{array}{l}\text { Autonomous } \\
\text { Private }\end{array}$ & $\begin{array}{l}\text { Trust } \\
\text { Personalization }\end{array}$ & $\begin{array}{l}\text { Newsgroup } \\
\text { Email/Phone }\end{array}$ & Innovation \\
\hline
\end{tabular}

Figure 5: Processes by which Knowledge is Activated

The case studied in this paper illustrates that the activation of knowledge identities and their appropriate activation effects, the knowledge paradox can be overcome. In this, the role of electronic collaboration is to bridge boundaries through mediating collaborative technologies. For accountable knowledge to be exchanged, the meanings have to be the same in the minds of the receiver and communicator. Shared spaces that enable different perceptions of meaning to be exchanged are required. Electronic collaboration technologies such as the Virtual Office provides the spaces upon which shared understanding can develop and accountable knowledge activated on demand. But it is information support provided by the electronic media that enables accountable knowledge to remain updated. Once activated through these effects, mediated by the Virtual Office suite, news feeds and intelligent searches, accountable knowledge is best suited to actions in which the deliverables are distinct such as the development of products. 
Discretionary knowledge is exchanged and activated through voluntary participation. The activation effects needed to activate discretionary knowledge are reciprocity in interactions mediated not only through technology but also a facilitator who sets and moderates rules of engagement. Collaborative tools for reciprocity are those that develop interactivity by fostering involvement and mutuality such as the Knowledge Marketplace described in this paper. The emergence of relationships through electronic collaboration appears to be an outcome of the activation of discretionary knowledge. Yet the activation of discretionary knowledge also requires relationship building to be successful. The discussion boards on the Knowledge Marketplace and homepages can enable relationships to built upon the identification of individual interests. Discretionary knowledge appears to best serve action where multiple alternatives are discussed in problem solving situations.

Autonomous knowledge forms the private and personal identity of an individual. The activation effects for bringing autonomous knowledge into action are the existence of trust whereby the risk of sharing aspects of one's private identity with the community is minimal. The flexibility with which collaborative technologies may be used to share aspects of an individual's personal identity effects the extent to which autonomous knowledge can be activated. It appears that the personalization of work environments and the flexibility with which collaborative technologies support this, enable autonomous knowledge to be activated in creative interactions. Together with the learning that may take place in communities of practice, these activation effects suggest that autonomous knowledge is particularly valuable in hybrid projects that entail innovation.

\section{Conclusion}

This research defines and develops a theoretical framework of knowledge activation. This adds to the knowledge management literature by developing a notion of knowledge-as-identity that is brought into action through activation effects. The mediating role of electronic collaboration in activating knowledge is an important one. The analysis of the case studied in this paper suggests that by mediating the activation effects needed to bring knowledge into action, electronic collaboration enables the knowledge paradox to be overcome. By mediating the existence of shared spaces and information support, electronic collaboration enables accountable knowledge to be activated. By capturing communities of practice in which reciprocity and relationships develop, electronic collaboration enables discretionary knowledge to be activated. Electronic collaboration may also enable the personalization of work environments and the maintenance of trust. When the activation effects are in place, autonomous knowledge can be brought into action in creative hybrid projects. This perspective 
of electronic collaboration has implications for the activation of dispersed knowledge for the creation of customised, goods and services. Collaborative technology support must match the activation effects if it is to mediate the activation of knowledge into action.

\section{References}

S. Alexander, "Collaborative Commerce". ComputerWorld. July 2000. http://www.computerworld.com/softwaretopics/software/story/0,10801,46547,00.html

C.D. Argyris, and D. A. Schoen. Organizational Learning: A Theory of Action Perspective. Addison-Wesley, London. 1978.

C. Barnard, "The Function of the Executive." Harvard University Press. Cambridge. 1938.

A. L. Blanchard and M. L. Markus "The Experienced "Sense" of a Virtual Community: Characteristics and Processes." The DATA BASE for Advances in Information Systems. Vol. 35 no.1, pp 65-79. 2004.

B. Bechky "Sharing meaning Across Occupational Communities: The Transformation of Understanding on a Production Floor". Organization Science, Vol 14 no. 3, pp. 312-330. 2003.

M. Boisot, Knowledge Assets. Oxford University Press, Oxford. 1998.

J. Burgoon, J. A. Bonito, B. Bengtsson, A Ramirez, N. Dunbar and N. Miczo. "Testing the Interactivity Model: Communication Processes, Partner Assessments, and the Quality of Collaborative Work." Journal of Management Information Systems. Vol 16.No 3. p.33-56. 2000.

R. Charan "How Networks Reshape Organizations for Results" Harvard Business Review. pp104-115. 1991.

R.L. Daft, and K.E. Weick. Toward a model of organizations as interpretation systems. Academy of Management Review. Iss 9. pp: 284-295. 1984.

T.H. Davenport, S.L. Jarvenpaa, and M. Beers, "Improving Knowledge Work Processes". Sloan Management Review. Pp: 53-65. Summer 1996.

G. DeSanctis, and P. Monge, "Communication processes for virtual organizations." Journal of Computer Mediated Communication. Vol 3, No.4, pp. 1-21. 1998.

P. Drucker, "The Coming of the New Organisation." Harvard Business Review. pp. 45-53. 1988.

R. Duncan, and A. Weiss, "Organizational learning: Implications for organizational design." in: B.Straw, L.L.Cummings (eds) Research in Organizational Behavior. Vol 1, pp75-132. JAI, Greenwich. 1979.

Y. Engeström, R. Engeström, and M. Kärkkäinen, "Polycontextuality and Boundary Crossing in Expert Cognition: Learning and Problem Solving in Complex Work Activities." Learning and Instruction, Iss 5. pp 319-336. 1995.

M. El-Shinnawy and L. Markus, "Acceptance of Communications Media in Organizations: Richness or Features?" IEEE Transactions on Professional Communication. New York: Vol 41, No 4 pp.242-253. 1998.

B. S. Eom, and C.K. Lee, "Virtual Teams: An Information Age Opportunity for Mobilizing Hidden Manpower," SAM Advanced Management Journal, pp.12-15. Spring 1999. 
J. Fulk, and G. DeSanctis "Electronic Communication for Changing Organizational Forms". Organisation Science. Vol 6, Iss. 4. pp 337-349. 1995.

B.G. Glaser, and A.L. Straus, The Discovery of Grounded Theory: Strategies for Qualitative Research. Aldine de Gruyter:New York. 1967.

J. Galaskiewicz, Exchange Networks and Community Politics. London:Sage Publications. 1979.

M.T. Hansen, N. Nohria, and T. Tierney, "What's your Strategy for Managing Knowledge?" Harvard Business Review. March-April 1999.

J. Hibbard, and K.M. Carillo, "Knowledge Revolution - Getting employees to share what they know is no longer a technology challenge - it's a corporate culture challenge," InformationWeek. Pp 663. 1998.

C.W. Holsapple, and A.B. Whinston. "Knowledge-based Organizations." Information Society. Iss 2. pp 77-89. 1987.

A.C. Inkpen and A. Dinur, "Knowledge Management Processes and International Joint Ventures," Organization Science, Vol 9. no.4, pp. 454-468, 1998.

S. Jarvenpaa, K. Knoll, D. and Leidner, D. "Antecedents of Trust in Global Teams," Journal of MIS. Vol 14, Iss 4. pp 29-64. 1998.

R.M. Kanter, The Change Masters. New York:Unwin. 1983.

D. Knoke, and J. H. Kulksinki. "Network Analysis: Basic Concepts". in: G. Thompson, J. Frances, R. Levacic and J. Mitchell (Eds), Markets, Hierarchies and Networks The Coordination of Social Life. London:Sage. 1991.

S. Kownslar "Collaborative Commerce." ACM Ubiquity. Retrieved February 232004. http://www.acm.org/ubiquity/views/s_kownslar_1.html

N. Kock, "Compensatory Adaptation to a Lean Medium: An Action Research Investigation of Electronic Communication in Process Improvement Groups." IEEE Transactions on Professional Communication. New York: Vol 44. No 4. pp 267-285. 2001.

J. Lave, and E. Wenger, Situated Learning. Legitimate Peripheral Participation. Cambridge: Cambridge University Press. 1991.

M. Lea, T. O'Shea, and P. Fung, "Constructing the Network Organization: Content and Context in the Development of Electronic Communications." Organization Science. Vol 6, Iss 4, pp.462-478. 1995.

J. Lipnack, and J. Stamps, Virtual Teams: Reaching Across Space, Time and Organizations with Technology. John Wiley and Sons. 1997.

J. Morrison, M. Morrison, and D. Vogel, "Software to Support Business Teams," Group Decision and Negotiation, September, pp. 91-115. 1992.

J.F. Nunamaker, D.R. Vogel, A. Heminger, B. Martz, R. Grohowski, and C. McGoff, "Experiences at IBM with GSS." Decision Support Systems, Vol 5, Iss. 2. pp 183-196. 1989.

I. Nonaka, and H. Takeuchi, The Knowledge Creating Company. Oxford University Press. Oxford. 1995.

C. Perin, "Electronic Social Fields in Bureaucracies". Communications of the ACM. 34(12):75-82. 1991.

M. Polanyi, The Tacit Dimension. Routledge and Kegan Paul, London. 1966. 
A. Powell, G. Piccoli, and B. Ives. "Vitual Teams: A Review of Current Literature and Directions for Future Research". The Database for Advances in Information Systems. 35(1):6-36. 2004.

W. W. Powell, "Neither market nor hierarchy: network forms of organization." in: G. Thompson, J. Frances, R. Levacic and J. Mitchell (Ed), Markets, Hierarchies and Networks the Coordination of Social Life. Sage. London. 1991.

S. Qureshi, and D. Vogel. "Organizational Adaptiveness in Virtual Teams". Group Decision and Negotiation. Vol 10, Iss.1, pp 27-46 2001.

S. Qureshi, I Bogenrieder, and K. Kumar. "Managing Participative Diversity in Virtual Teams: Requirement for Collaborative Technology Support.", in: (Eds) R. Sprague and J. Nunamaker, The Thirty Third Hawaii International Conference in Systems Sciences. IEEE Computer Society Press. 2000.

J.B. Quinn, Intelligent Enterprise. Free Press. New York.1992.

A. F. Rutkowski, D. R. Vogel, M. van Genuchten, T. Bemelmans, and M. Favier "E-collaboration: The reality of virtuality" IEEE Transactions on Professional Communication. New York: Dec 2002. Vol. 45, Iss. 4; p. 219

C.P. Ruppel and S. Harrington. "Sharing Knowledge Through Intranets: A Study of Organizational Culture and Intranet Implementation." IEEE Transactions on Professional Communication. Vol 4. No.1, pp 37-52. 2001.

D. Robey, H.M. Khoo, and C. Powers. "Situated Learning in Cross Functional Virtual Teams. " IEEE Transactions on Professional Communication. Vol.42, Iss 1. pp 51-66. 2000.

T. A. Stewart. Intellectual Capital: The New Wealth of Organizations. Currency Doubleday. 1997.

M. Schrage, Shared Minds: The New Technologies of Collaboration. New York. Random House. 1990.

P. M. Senge, The Fifth Discipline: The Age and Practice of the Learning Organization. London: Century Business. 1990.

L. Sherry and K. Myers. "The Dynamics of Collaborative Design." IEEE Transactions on Professional Communication. Vol 41. No 2., pp 123-139, 1998.

A. Straus, and J. Corbin, Basics of Qualitative Research: Techniques and Procedures for Developing Grounded Theory. Thousand Oaks,London:Sage. 1998.

K.E. Weick, "Theory Building as Disciplined Imagination". Academy of Management Review. 14(2), 1989.

E. Wenger, Communities of Practice: Learning, Meaning and Identity. Cambridge: Cambridge Oxford University Press. 1998.

O. Williamson, Organization Theory. Oxford University Press. 1995.

M. Zack, Managing Codified Knowledge. Sloan Management Review. Pp45-58. 1999. 


\section{Publications in the Report Series Research* in Management}

\section{ERIM Research Program: "Business Processes, Logistics and Information Systems"}

\section{4}

Smart Pricing: Linking Pricing Decisions with Operational Insights

Moritz Fleischmann, Joseph M. Hall and David F. Pyke

ERS-2004-001-LIS

http://hdl.handle.net/1765/1114

Mobile operators as banks or vice-versa? and: the challenges of Mobile channels for banks

L-F Pau

ERS-2004-015-LIS

http://hdl.handle.net/1765/1163

Simulation-based solution of stochastic mathematical programs with complementarity constraints: Sample-path analysis S. Ilker Birbil, Gül Gürkan and Ovidiu Listeş ERS-2004-016-LIS

http://hdl.handle.net/1765/1164

Combining economic and social goals in the design of production systems by using ergonomics standards Jan Dul, Henk de Vries, Sandra Verschoof, Wietske Eveleens and Albert Feilzer

ERS-2004-020-LIS

http://hdl.handle.net/1765/1200

Factory Gate Pricing: An Analysis of the Dutch Retail Distribution

H.M. le Blanc, F. Cruijssen, H.A. Fleuren, M.B.M. de Koster

ERS-2004-023-LIS

http://hdl.handle.net/1765/1443

A Review Of Design And Control Of Automated Guided Vehicle Systems

Tuan Le-Anh and M.B.M. De Koster

ERS-2004-030-LIS

http://hdl.handle.net/1765/1323

Online Dispatching Rules For Vehicle-Based Internal Transport Systems

Tuan Le-Anh and M.B.M. De Koster

ERS-2004-031-LIS

http://hdl.handle.net/1765/1324

Generalized Fractional Programming With User Interaction

S.I. Birbil, J.B.G. Frenk and S. Zhang

ERS-2004-033-LIS

http://hdl.handle.net/1765/1325

\footnotetext{
* A complete overview of the ERIM Report Series Research in Management: https://ep.eur.nl/handle/1765/1

ERIM Research Programs:

LIS Business Processes, Logistics and Information Systems

ORG Organizing for Performance

MKT Marketing

F\&A Finance and Accounting

STR Strategy and Entrepreneurship
} 
Meta-heuristics for dynamic lot sizing: A review and comparison of solution approaches

Raf Jans and Zeger Degraeve

ERS-2004-042-LIS

http://hdl.handle.net/1765/1336

Reinventing Crew Scheduling At Netherlands Railways

Erwin Abbink, Matteo Fischetti, Leo Kroon, Gerrit Timmer And Michiel Vromans

ERS-2004-046-LIS

http://hdl.handle.net/1765/1427

Intense Collaboration In Globally Distributed Teams: Evolving Patterns Of Dependencies And Coordination

Kuldeep Kumar, Paul C. van Fenema and Mary Ann Von Glinow

ERS-2004-052-LIS

http://hdl.handle.net/1765/1446

The Value Of Information In Reverse Logistics

Michael E. Ketzenberg, Erwin van der Laan and Ruud H. Teunter

ERS-2004-053-LIS

http://hdl.handle.net/1765/1447

Cargo Revenue Management: Bid-Prices For A 0-1 Multi Knapsack Problem

Kevin Pak and Rommert Dekker

ERS-2004-055-LIS

http://hdl.handle.net/1765/1449

Real-Time Scheduling Approaches For Vehicle-Based Internal Transport Systems

Tuan Le-Anh and M.B.M. De Koster

ERS-2004-056-LIS

http://hdl.handle.net/1765/1452

Activating Knowledge Through Electronic Collaboration: Vanquishing The Knowledge Paradox

S. Qureshi and P. Keen

ERS-2004-058-LIS

A Grounded Theory Analysis Of E-Collaboration Effects For Distributed Project Management

S. Qureshi, M. Liu and D. Vogel

ERS-2004-059-LIS

http://hdl.handle.net/1765/1448

Satisfaction Attainment Theory As A Model For Value Creation

R.O. Briggs, S. Qureshi and B. Reining

ERS-2004-062-LIS

http://hdl.handle.net/1765/1450 